\title{
A Nomogram Predicting Prostate Cancer-Specific Mortality after Radical Prostatectomy
}

\author{
Christopher R. Porter ${ }^{a}$ Nazareno Suardi ${ }^{b, c}$ Umberto Capitanio ${ }^{\text {b, c }}$ \\ Georg C. Hutterer $^{b}$ Koichi Kodama ${ }^{a}$ Robert P. Gibbons ${ }^{a}$ Roy Correa Jr. ${ }^{a}$ \\ Paul Perrotte $^{\mathrm{b}} \quad$ Francesco Montorsic $^{\mathrm{c}}$ Pierre I. Karakiewicz ${ }^{\mathrm{b}}$ \\ ${ }^{\mathrm{a}}$ Department of Urology, Virginia Mason Medical Center, Seattle, Wash., USA; ${ }^{\mathrm{b}}$ Cancer Prognostics and Health \\ Outcomes Unit, University of Montreal, Montreal, Que., Canada; ' ${ }^{\mathrm{D}}$ epartment of Urology, Vita-Salute University \\ San Raffaele, Milan, Italy
}

\section{Key Words}

Prostate cancer $\cdot$ Radical prostatectomy $\cdot$ Cancer-specific mortality $\cdot$ Nomogram

\begin{abstract}
Objective: We describe a model capable of predicting prostate cancer (PCa)-specific mortality up to 20 years after a radical prostatectomy (RP), which can adjust the predictions according to disease-free interval. Patients and Methods: 752 patients were treated with RP for organ-confined PCa. Cox regression modeled the probability of PCa-specific mortality. The significance of the predictors was confirmed in competing risks analyses, which account for other-cause mortality. Results: The mean follow-up was 11.4 years. The 5-, 10-, 15- and 20-year actuarial rates of PCa-specific survival were 99.0, 95.5, 90.9 and $85.7 \%$, respectively. RP Gleason sum ( $p<0.001)$, pT stage $(p=0.007)$, adjuvant radiotherapy $(p=0.03)$ and age at RP $(p=0.004)$ represented independent predictors of PCa-specific mortality in the Cox regression model as well as in competing risks regression. Those variables, along with lymph node dissection status $(p=0.4)$, constituted the nomogram predictors. After 200 bootstrap resamples, the nomogram achieved 82.6, 83.8, 75.0 and $76.3 \%$ accuracy in predicting PCa-specific mortality
\end{abstract}

at 5, 10, 15 and 20 years post-RP, respectively. Conclusions: At 20 years, roughly $20 \%$ of men treated with RP may succumb to PCa. The current nomogram helps to identify these individuals. Their follow-up or secondary therapies may be adjusted according to nomogram predictions.

Copyright $\odot 2010$ S. Karger AG, Basel

\section{Introduction}

Radical prostatectomy (RP) represents a widely used treatment modality for organ-confined prostate cancer (PCa) [1-6]. Unfortunately, up to $41 \%$ of patients treated with RP develop biochemical recurrence [7-11]. Of the patients with biochemical recurrence, $8-17 \%$ die of $\mathrm{PCa}$ [12-14].

Although several instruments can predict the individual probability of biochemical recurrence after RP [10, 15-17], only two models can approximate the risk of PCaspecific mortality $[13,18]$. Instead of providing individual estimates, these existing models only provide group

\section{C.R. Porter and N. Suardi equally contributed to this paper.}

\section{KARGER}

Fax +4161306 1234

E-Mail karger@karger.ch

www.karger.com
(C) 2010 S. Karger AG, Basel

$0042-1138 / 10 / 0842-0132 \$ 26.00 / 0$

Accessible online at:

www.karger.com/uin
Pierre I. Karakiewicz, MD, FRCSC

Director, Cancer Prognostics and Health Outcomes Unit, University of Montreal Health Center (CHUM), 1058, rue St-Denis, Montreal, Que. H2X 3J4 (Canada) Tel. +1 5148908000 ext. 35336, Fax +1 5142275103

E-Mail pierre.karakiewicz@umontreal.ca 
averages. Moreover, they are limited to patients with established biochemical relapse $[13,18]$. In clinical practice, patients treated with RP want to know their individual prognosis once the pathological disease staging has been performed and well before several serial quarterly postoperative prostate-specific antigen (PSA) measurements have been obtained and determined to be indicative of biochemical recurrence. To address this void, we decided to develop and internally validate a nomogram predicting the individual probability of PCa-specific mortality in patients treated with RP for clinically localized PCa using a cohort of 752 patients with available long-term follow-up $[19,20]$.

\section{Patients and Methods}

\section{Patient Population}

Between December 1954 and May 1994, 787 patients underwent RP at Virginia Mason Medical Center by 13 surgeons [19]. 35 men were excluded due to missing age at surgery (9) or a pathologic T stage (26). Clinical and pathological data were logged into a prospective database by one of the authors (R.P.G.) from 1969 to 1999. In later years, the records were maintained electronically with institutional review board approval.

Of the remaining 752 patients, none received neoadjuvant therapy. Preoperative comorbidity was defined according to the Charlson weighted index of comorbidity [21]. For purposes of analyses, patients with an index of 2-4 were grouped with those who had an index of 1 . Perineal RP was performed in 428 patients (56.9\%) and 324 (43.1\%) underwent retropubic RP. Pelvic lymph node dissection at surgery was performed in 342 patients (45.5\%) as previously described [19]. Lymph node dissection pathologies were not recorded in the database and could not be included in the current analyses. From 1992 to 1994, tumors were routinely classified according to the Gleason grading system [22]. Before 1992, tumor grade was recorded as well differentiated (I), moderately differentiated (II) and poorly differentiated (III). We recoded these data according to Roehl et al. [9]. Positive surgical margins were defined as the presence of cancer cells against the inked resection margin.

118 patients (15.7\%) received adjuvant radiotherapy between 1 and 3 months after RP. Since adjuvant radiotherapy represents an early event and the decision to administer adjuvant radiotherapy is made virtually immediately after RP, we included adjuvant radiotherapy within the predictors of PCa-specific mortality. Conversely, clinical events such as local recurrence, distant recurrence, hormonal therapy or salvage radiotherapy were not considered in the model, as these events occur well after RP and, therefore, cannot be used for prognostication at the time of RP.

Cause of death was ascertained according to detailed chart review or was obtained from the Virginia Mason Medical Center cancer registry, which uses links with the Washington State Death Certificate Office. PCa had to be the first listed cause of death on the certificate for a patient to be classified as having died from PCa. The last data follow-up was performed on December 1st, 2004.

Nomogram Predicting Prostate

Cancer-Specific Mortality
Statistical Analysis

The cohort of 752 patients was used to develop and internally validate the postoperative nomogram for the prediction of $\mathrm{PCa}$ specific mortality. Age at surgery, pathological stage (TNM 1992), positive surgical margin status, pathologic Gleason sum, surgical procedure (retropubic vs. perineal), pelvic lymph node dissection status (performed vs. not performed), comorbidity extent and delivery of adjuvant radiotherapy were used as predictors in univariable and multivariable Cox regression models addressing PCa-specific mortality. The predictive accuracy and statistical significance of all predictors were quantified in univariable analyses. Subsequently, all predictors were included in a multivariable model. Stepwise backward variable removal was applied to the model with the intent of identifying the most accurate and parsimonious set of predictors.

Competing risks regression was used to test the significance of PCa-specific mortality predictors after accounting for othercause mortality. The effect of other-cause mortality cannot be accounted for in Cox regression models. However, the use of competing risks regression, as described by Fine and Gray [23], can remove this limitation. Unfortunately, there are no commercially available statistical packages that allow applying competing risks regression within a nomogram setting. Consequently, the nomogram was based on Cox regression models.

The accuracy of the final multivariable model was quantified using 200 bootstrap resamples that were applied to its regression coefficients. Since we relied on censored data, Harrell's concordance index substituted the area under the receiver operating characteristics curve. Specific accuracy estimates were calculated for $5,10,15$ and 20 years. To test the nomogram performance characteristics, we used the val.surv calibration method devised for censored data. All statistical analyses were performed with S-Plus ${ }^{\circledR}$ Professional, version 1 (MathSoft Inc., Seattle, Wash., USA) and statistical significance was set at 0.05 . All studies were undertaken with the approval and oversight of the Institutional Review Boards for the protection of human subjects.

\section{Results}

Patient characteristics are shown in table 1. Mean age at RP was 63.6 years (median 64.4, range $42.9-77.9$ ). At RP, 341 patients (45.3\%) had pT3 disease, 63 (8.4\%) had a Gleason sum $\geq 8$ and positive surgical margin(s) were present in 283 (37.6\%). Mean follow-up was 11.6 years (median 11.4, range 0.1-40.5). 50 patients (6.6\%) died of PCa during follow-up, and 248 (33.0\%) died of other causes. In men who died of PCa, the median time to death was 9.1 years (mean 10.9, range 1.5-27.0). The median actuarial time to PCa-specific mortality was not reached (mean 34.8 years) in the overall cohort.

Figure la shows the actuarial PCa-specific survival at $5,10,15$ and 20 years post-RP, which was $99.0,95.5,90.9$ and $85.7 \%$, respectively. Figure $1 \mathrm{~b}$ shows the rate of othercause mortality at 5, 10, 15 and 20 years, which was 5.6, $16.0,32.8$ and $48.6 \%$, respectively. Figure 1 also shows 
Table 1. Descriptive characteristics for 752 assessable patients

\begin{tabular}{|c|c|}
\hline Variables & Number of patients ${ }^{1}$ \\
\hline \multicolumn{2}{|l|}{ Age } \\
\hline Mean (median) & $63.6(64.4)$ \\
\hline Range $42.9-64.6$ & $383(50.9 \%)$ \\
\hline Range 64.7-77.9 & $369(49.1 \%)$ \\
\hline \multicolumn{2}{|l|}{ Study period } \\
\hline 1954-1987 & $389(51.7 \%)$ \\
\hline 1988-1994 & $363(48.3 \%)$ \\
\hline \multicolumn{2}{|l|}{ pT stage (1992) } \\
\hline $\mathrm{T} 2 \mathrm{a}$ & $177(23.5 \%)$ \\
\hline $\mathrm{T} 2 \mathrm{~b} / \mathrm{c}$ & $234(31.1 \%)$ \\
\hline $\mathrm{T} 3$ & $341(45.3 \%)$ \\
\hline Positive surgical margin & $283(37.6 \%)$ \\
\hline \multicolumn{2}{|l|}{ Gleason sum } \\
\hline $2-5$ & $220(29.2 \%)$ \\
\hline 6 & $299(39.8 \%)$ \\
\hline 7 & $170(22.6 \%)$ \\
\hline $8-10$ & $63(8.4 \%)$ \\
\hline \multicolumn{2}{|l|}{ Surgical procedure } \\
\hline Perineal & $428(56.9 \%)$ \\
\hline Retropubic & $324(43.1 \%)$ \\
\hline Lymph node dissection & $342(45.5 \%)$ \\
\hline \multicolumn{2}{|l|}{ Comorbidities } \\
\hline 0 & $685(91.1 \%)$ \\
\hline$\geq 1$ & $67(8.9 \%)$ \\
\hline Adjuvant radiotherapy & $118(15.7 \%)$ \\
\hline Hormonal therapy & $114(15.1 \%)$ \\
\hline \multicolumn{2}{|l|}{ Year of surgery } \\
\hline Range & 1954-1994 \\
\hline PCa-specific mortality & $50(6.6 \%)$ \\
\hline \multicolumn{2}{|c|}{ Time to death from PCa, years } \\
\hline Mean (median) & $10.9(9.1)$ \\
\hline Range & $1.5-27.0$ \\
\hline Other-cause mortality & $248(33.0 \%)$ \\
\hline \multicolumn{2}{|c|}{ Time to death from other causes, years } \\
\hline Mean (median) & $12.3(11.7)$ \\
\hline Range & $0-33.8$ \\
\hline \multicolumn{2}{|l|}{ Follow-up time, years } \\
\hline Mean (median) & $11.6(11.4)$ \\
\hline Range & $0.1-40.5$ \\
\hline \multicolumn{2}{|c|}{ Actuarial time to PCa-specific mortality, years } \\
\hline Mean (median) & 34.8 (not reached) \\
\hline
\end{tabular}

the rate of $\mathrm{PCa}$-specific survival stratified according to the tested variables (fig. $1 \mathrm{c}-\mathrm{j}$ ).

The univariable analyses replicated the relationships described with the Kaplan-Meier survival curves (table 2). Table 2 also shows the multivariable Cox regression models predicting $\mathrm{PCa}$-specific mortality after RP.
In the full multivariable model, pathologic Gleason sum $(p<0.001)$, pathologic T stage $(p=0.01)$, age at surgery $(\mathrm{p}=0.02)$ and the delivery of adjuvant radiotherapy $(\mathrm{p}=0.02)$ represented independent predictors of PCaspecific mortality. After stepwise backward variable elimination, all nonsignificant predictors of PCa-specific mortality, except for pelvic lymph node dissection status, were removed. Despite lack of independent predictor status, pelvic lymph node dissection status was left in the final model as it increased predictive accuracy. The final multivariable model is shown in table 2 .

Table 3 lists univariable and multivariable competing-risks regression models that were developed from the cohort of 752 patients. In the multivariate competing-risks regression model, all variables included in the final model, except for pelvic lymph node dissection status, represented statistically significant predictors of PCa-specific mortality after accounting for other-cause mortality.

After 200 bootstrap resamples of the nomogram regression coefficients, the combined predictive accuracy of the final multivariate model was $82.6,83.8,75.0$ and $76.3 \%$ at $5,10,15$ and 20 years post-RP, respectively. The final model (table 2) served as the basis for the multivariate nomogram (fig. 2a) to predict the individual probability of PCa-specific mortality. The nomogram predictions are shown for 5, 10, 15 and 20 years. At each time point, the prediction is accompanied by a graph that adjusts the PCa-specific mortality probability according to a specific disease-free follow-up interval after RP (fig. 2c$\mathrm{f})$. The determination of the probability of PCa-specific mortality is achieved in two steps. First, the nomogram axes are used to quantify the total number of risk points. Subsequently, this number is applied to one of the timespecific scales. For example, 15-year predictions are shown in figure $2 \mathrm{e}$. When the predictions are calculated immediately after RP, a patient with 155 risk points has a $20 \%$ probability of dying of $\mathrm{PCa}$, which declines to $15 \%$ at 96 months and further to $10 \%$ at 132 months, provided no disease relapse occurs until then.

Figure $2 \mathrm{~b}$ shows the calibration plot of the newly developed nomogram. The $45^{\circ}$ line represents the ideal predictions. The $\mathrm{x}$-axis indicates the probability of PCa-specific mortality predicted by the nomogram and the y-axis indicates the observed PCa-specific mortality rate. It is of note that the curve depicting the relationship between predicted and observed $\mathrm{PCa}$-specific mortality closely approximates the ideal predictions, which indicates excellent calibration. 


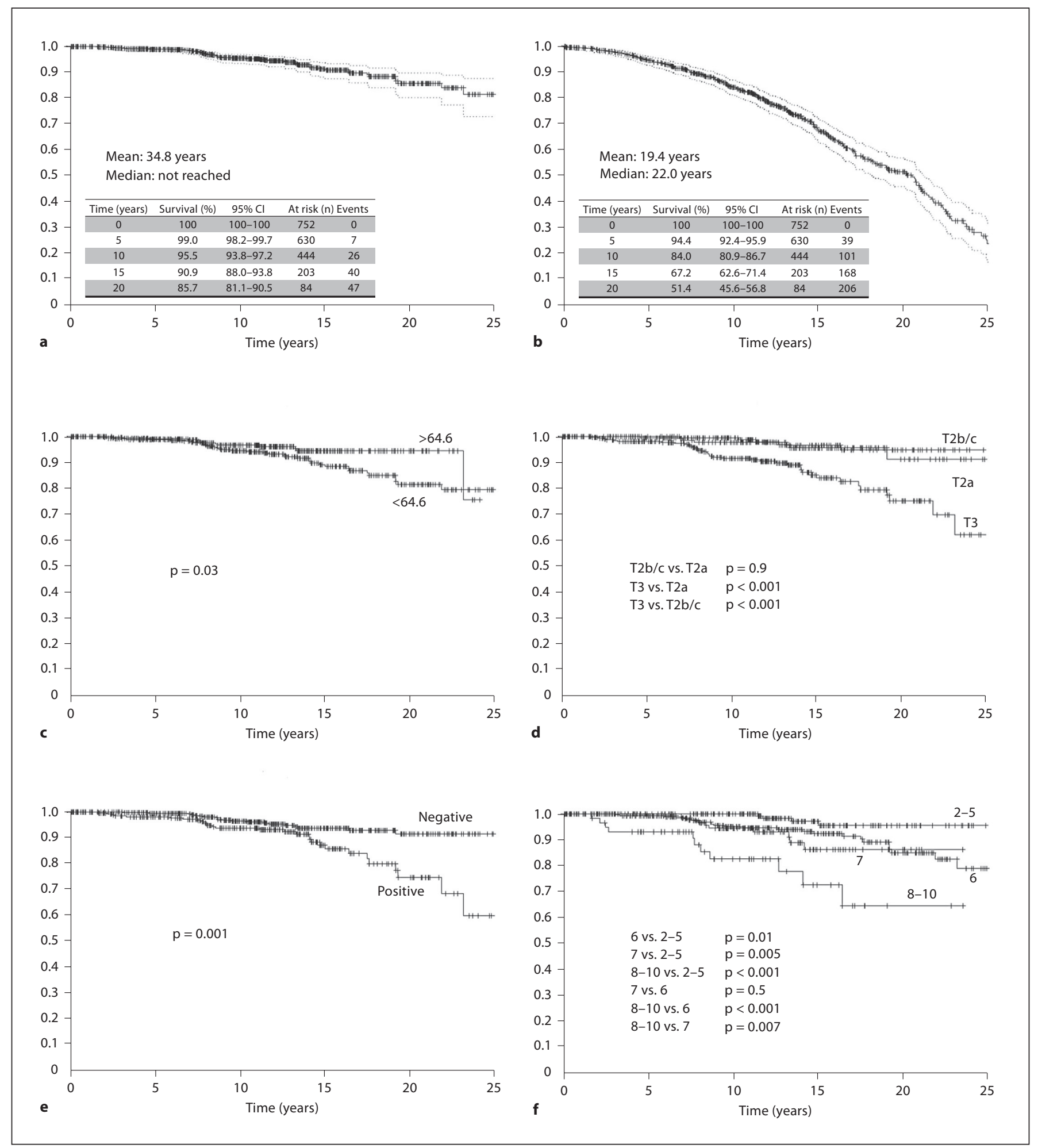

Fig. 1. a PCa-specific survival. b Other-cause mortality-free survival. c PCa-specific survival according to age at surgery. d Pathologic T stages. e Surgical margin status. f Pathologic Gleason sum. 


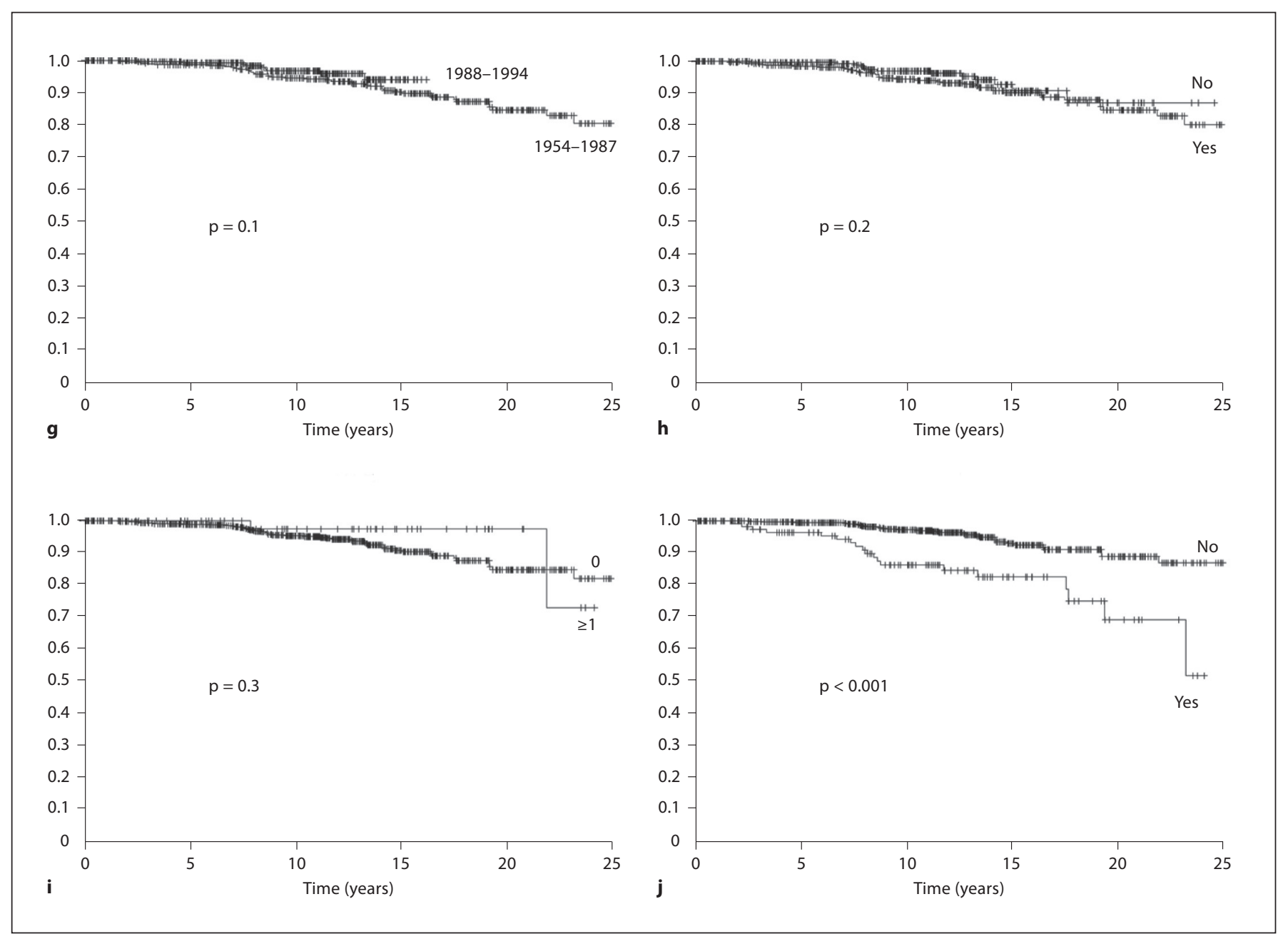

Fig. 1. g Year of surgery. $\mathbf{h}$ Presence or absence of lymph node dissection at RP. i Presence or absence of comorbidities. j Adjuvant radiotherapy status.

\section{Discussion}

Unfortunately, up to $41 \%$ of patients treated with RP may exhibit a PSA relapse [7, 24]. However, only $8-17 \%$ of patients with documented biochemical recurrence progress to PCa-specific mortality [12, 13]. Therefore biochemical recurrence is not a specific marker of PCa-specific mortality.

Currently, only two models may help in identifying patients at risk of PCa-specific mortality. The D'Amico et al. [18] model, developed in 1,095 newly diagnosed patients, quantifies the relative increase in PCa-specific mortality risk prediction according to PSA velocity strata. The Freedland et al. [13] model, developed in 379 patients with an established PSA recurrence after RP, pro- vides the relative $\mathrm{PCa}$-specific mortality risk according to post-RP PSA doubling time, as well other established variables [13]. Unfortunately many patients cannot be assessed with these models. The D'Amico et al. model [18] requires serial preoperative PSA measurements and cancer biopsy characteristics. PSA may not be available or may not be long enough to rule out the possibility of late recurrence. Biopsy Gleason score may inaccurately reflect the RP pathology $[25,26]$. Finally, both models provide group values, which only reflect the central tendencies but do not do justice to patients whose characteristics do not reflect these tendencies. Moreover, neither model provides estimates of PCa mortality at specific time points, e.g. at 5, 10 and 15 years after treatment. Similarly, neither model adjusts for disease-free follow- 
Table 2. Univariable and multivariable Cox regression analyses predicting PCa-specific mortality after RP

\begin{tabular}{|c|c|c|c|}
\hline \multirow[t]{2}{*}{ Predictors } & \multirow{2}{*}{$\frac{\text { Univariable }}{\text { RR }(95 \% \mathrm{CI}) ; \mathrm{p}}$} & \multicolumn{2}{|l|}{ Multivariable } \\
\hline & & $\begin{array}{l}\text { full model } \\
\text { RR (95\% CI); p }\end{array}$ & $\begin{array}{l}\text { reduced model } \\
\mathrm{RR}(95 \% \mathrm{CI}) ; \mathrm{p}\end{array}$ \\
\hline Gleason sum & $-;<0.001$ & $-;<0.001$ & $-;<0.001$ \\
\hline 6 vs. $2-5$ & $3.7(1.3-10.6) ; 0.01$ & $2.4(0.8-7.2) ; 0.1$ & $2.5(0.9-7.4) ; 0.09$ \\
\hline 7 vs. $2-5$ & $4.6(1.4-14.6) ; 0.01$ & $3.0(0.9-9.9) ; 0.07$ & $3.1(0.9-10.1) ; 0.06$ \\
\hline $8-10$ vs. $2-5$ & $13.9(4.4-43.8) ;<0.001$ & $10.5(3.3-33.8) ;<0.001$ & $10.8(3.4-34.4) ;<0.001$ \\
\hline Adjuvant radiotherapy & $3.6(2.0-6.5) ;<0.001$ & $2.1(1.1-4.2) ; 0.02$ & $2.0(1.1-3.9) ; 0.03$ \\
\hline Age $(>64.6$ vs. $\leq 64.6)$ & $0.5(0.3-1.0) ; 0.04$ & $0.4(0.2-0.8) ; 0.02$ & $0.4(0.2-0.7) ; 0.004$ \\
\hline pT stage & $-;<0.001$ & $-; 0.01$ & $-; 0.007$ \\
\hline T2b/c vs. T2a & $1.0(0.3-3.2) ; 1.0$ & $1.1(0.3-3.6) ; 0.8$ & $1.1(0.3-3.5) ; 0.9$ \\
\hline T3 vs. T2a & $4.6(1.9-11.0) ;<0.001$ & $3.8(1.4-10.7) ; 0.01$ & $3.3(1.3-8.5) ; 0.01$ \\
\hline PLND status (yes vs. no) & $0.7(0.4-1.3) ; 0.3$ & $0.6(0.2-2.0) ; 0.4$ & $0.7(0.3-1.3) ; 0.3$ \\
\hline Positive surgical margin & $2.6(1.5-4.6) ; 0.001$ & $0.8(0.4-1.7) ; 0.6$ & - \\
\hline Surgical procedure (retropubic vs. perineal) & $0.7(0.3-1.4) ; 0.3$ & $1.1(0.3-3.9) ; 0.9$ & - \\
\hline Comorbidities ( $\geq 1$ vs. 0 ) & $0.5(0.1-2.1) ; 0.4$ & $0.5(0.1-2.3) ; 0.4$ & - \\
\hline
\end{tabular}

PLND = Pelvic lymph node dissection; $\mathrm{RR}=$ risk ratio.

Table 3. Univariable and multivariable competing risks regression models for prediction of PCa-specific mortality after PR after accounting for other-cause mortality

\begin{tabular}{|c|c|c|c|}
\hline \multirow[t]{2}{*}{ Predictors } & \multirow{2}{*}{$\frac{\text { Univariable }}{\text { RR }(95 \% \mathrm{CI}) ; \mathrm{p}}$} & \multicolumn{2}{|l|}{ Multivariable } \\
\hline & & $\begin{array}{l}\text { full model } \\
\text { RR }(95 \% \mathrm{CI}) ; \mathrm{p}\end{array}$ & $\begin{array}{l}\text { reduced model } \\
\mathrm{RR}(95 \% \mathrm{CI}) ; \mathrm{p}\end{array}$ \\
\hline Gleason sum & $-;-$ & $-;-$ & $-;-$ \\
\hline 6 vs. $2-5$ & $3.8(1.3-10.9) ; 0.01$ & $2.5(0.9-7.1) ; 0.08$ & $2.6(0.9-7.4) ; 0.06$ \\
\hline 7 vs. $2-5$ & $4.3(1.4-13.6) ; 0.01$ & $3.1(1.0-10.0) ; 0.07$ & $3.2(1.0-10.1) ; 0.04$ \\
\hline $8-10$ vs. $2-5$ & $12.2(3.9-38.3) ;<0.001$ & $8.2(2.7-25.1) ;<0.001$ & $8.3(2.7-25.4) ;<0.001$ \\
\hline Adjuvant radiotherapy & $3.6(2.0-6.4) ;<0.001$ & $2.1(1.0-4.1) ; 0.03$ & $2.0(1.1-3.8) ; 0.03$ \\
\hline Age (>64.6 vs. $\leq 64.6)$ & $0.4(0.2-0.8) ; 0.008$ & $0.4(0.2-0.7) ; 0.003$ & $0.3(0.2-0.6) ; 0.001$ \\
\hline pT stage & $-;-$ & $-;-$ & $-;-$ \\
\hline T2b/c vs. T2a & $0.8(0.3-2.6) ; 0.8$ & $1.0(0.3-3.1) ; 1.0$ & $1.0(0.3-3.0) ; 1.0$ \\
\hline T3 vs. T2a & $4.0(1.7-9.5) ; 0.001$ & $3.3(1.2-9.0) ; 0.02$ & $2.9(1.2-7.3) ; 0.02$ \\
\hline PLND status (yes vs. no) & $0.7(0.3-1.3) ; 0.2$ & $0.7(0.2-2.4) ; 0.6$ & $0.7(0.3-1.3) ; 0.2$ \\
\hline Positive surgical margin & $2.5(1.4-4.3) ; 0.002$ & $0.8(0.4-1.7) ; 0.6$ & - \\
\hline Surgical procedure (retropubic vs. perineal) & $0.7(0.3-1.3) ; 0.3$ & $0.9(0.2-3.4) ; 0.9$ & - \\
\hline Comorbidities ( $\geq 1$ vs. 0 ) & $0.4(0.1-1.7) ; 0.2$ & $0.5(0.1-2.0) ; 0.3$ & - \\
\hline
\end{tabular}

PLND = Pelvic lymph node dissection; $\mathrm{RR}=$ risk ratio.

up. Finally, neither model has been externally validated.

To address the above limitations (with the exception of external validation) that applied to the previous models, we developed a nomogram that entirely relies on $\mathrm{PCa}$ characteristics at RP pathology and on the delivery of ad- juvant radiotherapy in the immediate post-RP period. As adjuvant radiotherapy is considered an indicator of treatment failure in some prognostic tools, it is not included among the predictors $[15,27]$.

Our nomogram does not require the input of PSA or the knowledge of biochemical recurrence status. More- 


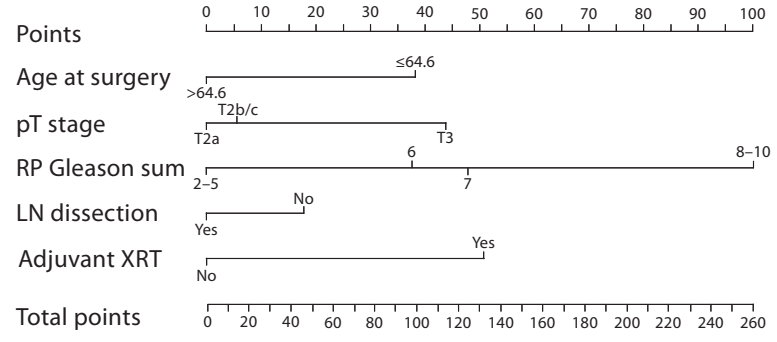

a
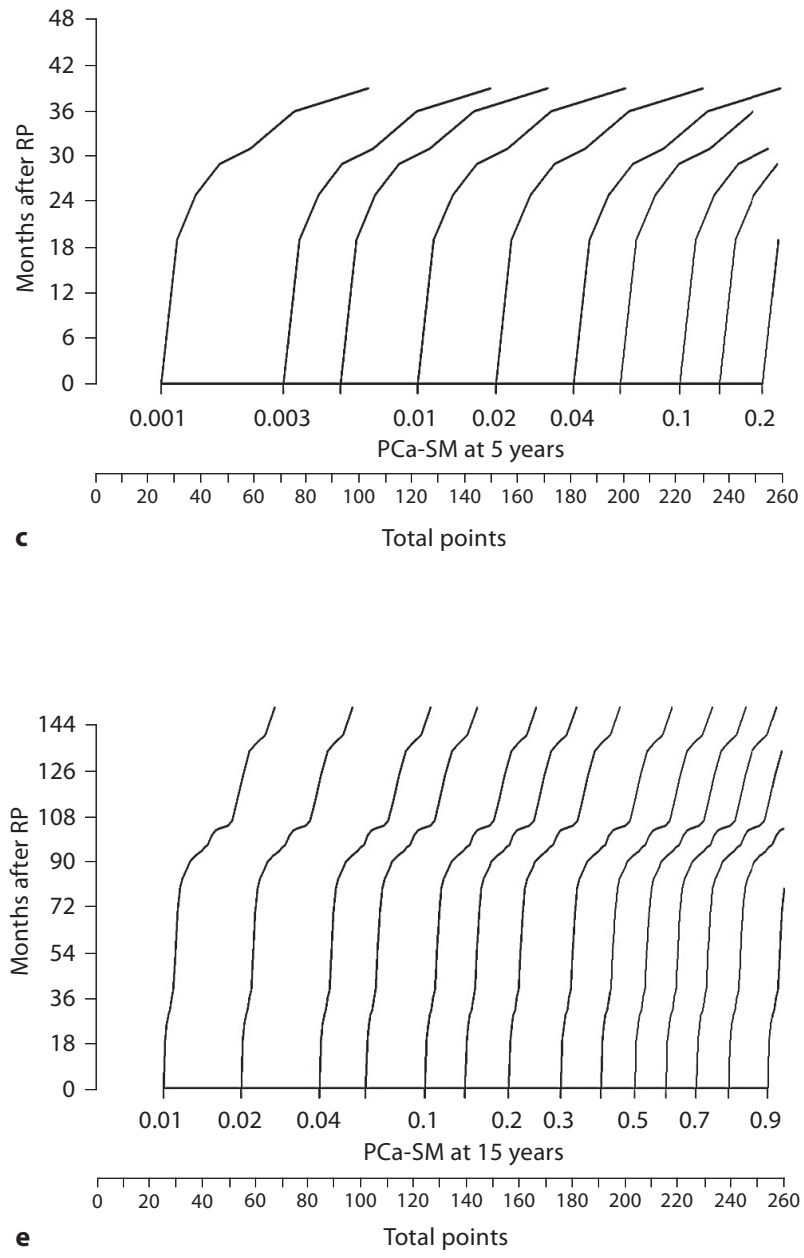
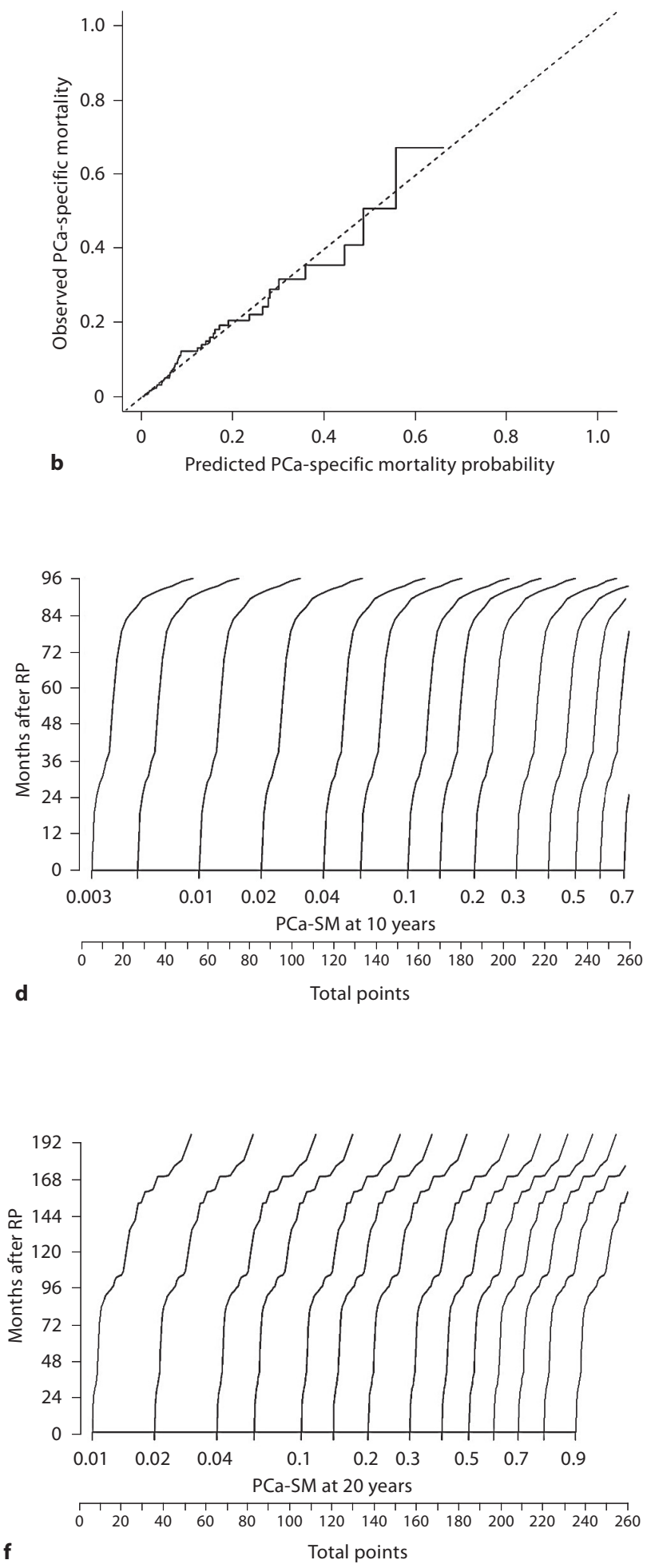
over, the tool makes predictions at different points in time after RP and its predictions are conditional on diseasefree interval. Finally, our model is one of few that were subjected to competing risks regression analyses, which confirmed the validity of its predictors after accounting for other-cause mortality. Importantly, our nomogram distinguishes itself from the previous models by its ability to quantify the individual probability of PCa-specific mortality instead of providing risk ratios for individual predictors. Individual predictions expressed on a $0-100 \%$ probability scale are more easily understood by patients and/or clinicians than relative rates or hazard rates.

Like the Freedland et al. [13] model, ours has been subjected to predictive accuracy testing. The Freedland et al. model was $83-84 \%$ accurate with minimal loss of discriminant properties after bootstrapping. Our model was $82.6,83.8,75.0$ and $76.3 \%$ accurate at $5,10,15$ and 20 years, respectively, when it was subjected to a simulated cohort of 150,400 patients (200 bootstrap resamples of 752 patients). Relative to the Freedland et al. [13] model which predicts from the time of biochemical recurrence, these accuracy values appear highly respectable, especially if one considers that our model predicts right after RP and many years prior to biochemical recurrence $[7,8]$.

The long-term nature of the data implies that recruitment needs to occur over a long period of time. The advantage of the long-term follow-up and its inherent long recruitment period include potential variability in surgical technique and pathological staging. The advantage resides in the capacity of the current model to predict PCa-specific mortality up to 20 years after surgery.

Despite its excellent predictive accuracy, our nomogram has several limitations. First, our series spans over a period of 40 years. Nevertheless, only 752 patients were included. This sample size limitation may undermine the generalizability of our findings. However, the similarity of PCa-specific mortality rates in other studies validates

Fig. 2. Nomogram (a) and calibration plot (b) for prediction of individual probability of PCa-specific mortality after RP. b The $45^{\circ}$ line represents the ideal prediction. The $\mathrm{x}$-axis indicates the nomogram-predicted $\mathrm{PCa}$-specific mortality probability and the $\mathrm{y}$-axis indicates the observed PCa-specific mortality fraction. It is of note that the curve depicting the relationship between predicted and observed PCa-specific mortality closely approximates the ideal predictions, which indicates excellent calibration. c PCaspecific mortality conditional prediction at 5 years. d PCa-specific mortality conditional prediction at 10 years. e PCa-specific mortality conditional prediction at 15 years. $\mathbf{P C a}$-specific mortality conditional prediction at 20 years. $\mathrm{SM}=$ Specific mortality. our data $[8,9,13]$. Second, although the pathologic Gleason sum represented the most powerful predictor of $\mathrm{PCa}$ specific mortality, the Gleason grading used in the present series has not been subjected to a review. Recently, Albertsen et al. [28] demonstrated a grade migration, especially in those with previously favorable Gleason sums. Therefore, our series cannot be compared to patients with a revised Gleason sum according to contemporary criteria. However, in clinical practice the great majority of patients will not benefit from a review of their original Gleason scores and most Gleason scores will be historic according to the Albertsen criteria [28]. Third, our nomogram was derived from a cohort of patients treated in North America. Different selection criteria for RP may have been used in Europe during the same time period, which may undermine the accuracy of our nomogram in European patients. Fourth, a large proportion of our patients who died from PCa (90\%) were treated with hormonal therapy after failure. Hormonal therapy has not been proven to prolong survival in patients with biochemical recurrence in randomized clinical trials [10]. Fifth, many important pathological data are missing in our cohort, including lymph node involvement and the distinction between pT3a and pT3b/c disease. Despite the lack of these crucial parameters, our nomogram resulted in high predictive accuracy in its validation. The performance of our nomogram may be improved through the inclusion of the pathological parameters mentioned above. Finally, our model was not subjected to external validation. Instead it was internally validated with bootstrapping, which represents the best substitute for an external validation cohort [29]. Moreover, we have demonstrated that accuracy recorded in bootstrap internal validation very closely approximates external validation in PCa cohorts [30].

\section{Conclusion}

RP provides excellent overall oncological outcomes in most patients affected by organ-confined PCa, but a proportion of patients treated with RP is at risk of PCa-specific mortality. We developed the first post-RP nomogram for individual prediction of PCa-specific mortality.

\section{Acknowledgment}

Dr. Pierre I. Karakiewicz is partially supported by the University of Montreal Urology Associates, Fonds de la Recherche en Santé du Québec, the University of Montreal Department of Surgery and the University of Montreal Foundation. 


\section{References}

1 Mohamad BA, Marszalek M, Brossner C, 11 Carini M, Masieri L, Minervini A, Lapini A, Ponholzer A, Wehrberger C, Willinger M, Madersbacher S: Radical prostatectomy in Austria: a nationwide analysis of 16,524 cases. Eur Urol 2007;51:684-688, discussion 689.

-2 Zorn KC, Gallina A, Hutterer GC, Walz J, Shalhav AL, Zagaja GP, Valiquette L, Gofrit ON, Orvieto MA, Taxy JB, Karakiewicz PI: External validation of a nomogram for prediction of side-specific extracapsular extension at robotic radical prostatectomy. J Endourol 2007;21:1345-1351.

$>3$ Heidenreich A, Aus G, Bolla M, Joniau S, Matveev VB, Schmid HP, Zattoni F: EAU guidelines on prostate cancer. Eur Urol 2008; 53:68-80.

4 Kessler TM, Burkhard FC, Studer UE: Nervesparing open radical retropubic prostatectomy. Eur Urol 2007;51:90-97.

$\checkmark 5$ Capitanio U, Scattoni V, Freschi M, Briganti A, Salonia A, Gallina A, Colombo R, Karakiewicz PI, Rigatti P, Montorsi F: Radical prostatectomy for incidental (stage T1a-T1b) prostate cancer: analysis of predictors for residual disease and biochemical recurrence. Eur Urol 2008;54:118-125.

-6 Barre C: Open radical retropubic prostatec tomy. Eur Urol 2007;52:71-80.

$>7$ Amling CL, Blute ML, Bergstralh EJ, Seay TM, Slezak J, Zincke H: Long-term hazard of progression after radical prostatectomy for clinically localized prostate cancer: continued risk of biochemical failure after 5 years. J Urol 2000;164:101-105.

$>8$ Han M, Partin AW, Pound CR, Epstein JI, Walsh PC: Long-term biochemical diseasefree and cancer-specific survival following anatomic radical retropubic prostatectomy. The 15-year Johns Hopkins experience. Urol Clin North Am 2001;28:555-565.

$>9$ Roehl KA, Han M, Ramos CG, Antenor JA, Catalona WJ: Cancer progression and survival rates following anatomical radical retropubic prostatectomy in 3,478 consecutive patients: long-term results. J Urol 2004;172: 910-914.

10 Simmons MN, Stephenson AJ, Klein EA: Natural history of biochemical recurrence after radical prostatectomy: risk assessment for secondary therapy. Eur Urol 2007;51: 1175-1184.
Serni S: Oncological and functional results of antegrade radical retropubic prostatectomy for the treatment of clinically localised prostate cancer. Eur Urol 2008;53:554-561.

12 Ward JF, Blute ML, Slezak J, Bergstralh EJ, Zincke $\mathrm{H}$ : The long-term clinical impact of biochemical recurrence of prostate cancer 5 or more years after radical prostatectomy. J Urol 2003;170:1872-1876.

13 Freedland SJ, Humphreys EB, Mangold LA, Eisenberger M, Dorey FJ, Walsh PC, Partin AW: Risk of prostate cancer-specific mortality following biochemical recurrence after radical prostatectomy. JAMA 2005;294:433439.

14 Porter CR, Suardi N, Kodama K, Capitanio U, Gibbons RP, Correa R, Jeldres C, Perrotte P, Montorsi F, Karakiewicz PI: A nomogram predicting metastatic progression after radical prostatectomy. Int J Urol 2008;15:889894.

15 Kattan MW, Wheeler TM, Scardino PT: Postoperative nomogram for disease recurrence after radical prostatectomy for prostate cancer. J Clin Oncol 1999;17:14991507.

16 Stephenson AJ, Scardino PT, Eastham JA, Bianco FJ Jr, Dotan ZA, DiBlasio CJ, Reuther A, Klein EA, Kattan MW: Postoperative nomogram predicting the 10 -year probability of prostate cancer recurrence after radical prostatectomy. J Clin Oncol 2005;23:70057012 .

17 Capitanio U, Ahyai S, Graefen M, Jeldres C, Shariat SF, Erbersdobler A, Schlomm T, Haese A, Steuber T, Heinzer H, Perrotte P, Peloquin F, Pharand D, Arjane P, Huland H, Karakiewicz PI: Assessment of biochemical recurrence rate in patients with pathologically confirmed insignificant prostate cancer. Urology 2008;72:1208-1211, discussion 1212-1213.

18 D’Amico AV, Chen MH, Roehl KA, Catalona WJ: Preoperative PSA velocity and the risk of death from prostate cancer after radical prostatectomy. N Engl J Med 2004;351:125135.

19 Porter CR, Kodama K, Gibbons RP, Correa R Jr, Chun FK, Perrotte P, Karakiewicz PI: 25-year prostate cancer control and survival outcomes: a 40-year radical prostatectomy single institution series. J Urol 2006;176: 569-574.

20 Capitanio U, Jeldres C, Shariat SF, Karakiewicz P: Clinicians are most familiar with nomograms and rate their clinical usefulness highest, look-up tables are second best. Eur Urol 2008;54:958-959.
21 Charlson ME, Pompei P, Ales KL, MacKenzie CR: A new method of classifying prognostic comorbidity in longitudinal studies: development and validation. J Chronic Dis 1987;40:373-383.

22 Gleason DF, Mellinger GT: Prediction of prognosis for prostatic adenocarcinoma by combined histological grading and clinical staging. J Urol 1974;111:58-64

23 Fine JP, Gray RJ: A proportional hazards model for the subdistribution of a competing risk. J Am Stat Assoc 1999;94:496-509.

24 Pound CR, Partin AW, Eisenberger MA, Chan DW, Pearson JD, Walsh PC: Natural history of progression after PSA elevation following radical prostatectomy. JAMA 1999;281:1591-1597.

25 King CR, Long JP: Prostate biopsy grading errors: a sampling problem? Int J Cancer 2000;90:326-330.

26 Chun FK, Briganti A, Shariat SF, Graefen M, Montorsi F, Erbersdobler A, Steuber T, Salonia A, Currlin E, Scattoni V, Friedrich MG, Schlomm T, Haese A, Michl U, Colombo R, Heinzer H, Valiquette L, Rigatti P, Roehrborn CG, Huland H, Karakiewicz PI: Significant upgrading affects a third of men diagnosed with prostate cancer: predictive nomogram and internal validation. BJU Int 2006;98:329-334.

27 Kattan MW, Eastham JA, Stapleton AM, Wheeler TM, Scardino PT: A preoperative nomogram for disease recurrence following radical prostatectomy for prostate cancer. J Natl Cancer Inst 1998;90:766-771.

28 Albertsen PC, Hanley JA, Barrows GH, Penson DF, Kowalczyk PD, Sanders MM, Fine J: Prostate cancer and the Will Rogers phenomenon. J Natl Cancer Inst 2005;97:12481253.

29 Steyerberg EW, Harrell FE Jr, Borsboom GJ, Eijkemans MJ, Vergouwe Y, Habbema JD: Internal validation of predictive models: efficiency of some procedures for logistic regression analysis. J Clin Epidemiol 2001;54: 774-781.

30 Chun FK, Graefen M, Briganti A, Gallina A, Hopp J, Kattan MW, Huland H, Karakiewicz PI: Initial biopsy outcome prediction - headto-head comparison of a logistic regressionbased nomogram versus artificial neural network. Eur Urol 2007;51:1236-1243. 